\title{
ТЕОРЕТИКО-ПРАВОВЫЕ АСПЕКТЫ ПОСРЕДНИЧЕСТВА С ПОЗИЦИИ ФУНКЦИОНАЛЬНОЙ ТЕОРИИ
}

\author{
(c) 2019 Фастова Марина Андреевна
}

кандидат юридических наук, доцент кафедры гражданского права, Юридический факультет Астраханский государственный университет, Россия, Астрахань

E-mail: romanenkoma82@mail.ru

\section{(c) 2019 Иванова Татьяна Михайловна}

старший преподаватель кафедры теории и истории государства и права, Юридический факультет Астраханский государственный университет, Россия, Астрахань

E-mail:krohmalt@mail.ru

Актуальность теоретико-методологической концепции посредничества определяется исключительной важностью проблем прав человека в социально-экономической, политической, правовой и духовной сферах нашего общества, а также противоречивым, конфликтным состоянием общественных отношений, особенно обостряющимся в периоды реформ и нововведений. В связи с тем, что посредничество - сложное многоаспектное социально-правовое явление, его теоретико-методологическая концепция базируется на комплексной научной структурно-функциональной ориентации, заключающейся в изучении данного общеправового института как целостного объекта не только с правовых, но и общеконфликтологических, социальных, экономических, психологических позиций. Такой процесс познания предполагает необходимость использования комплексной методологии, позволяет рассматривать посредничество как сложную систему, раскрывающуюся с помощью структурно-функционального анализа. Настоящая статья посвящена анализу посредничества с позиции именно функциональной теории, как части структурно-функционального анализа. Именно с помощью функционального анализа раскрывается сущность посредничества как общеправового института, выявляются взаимосвязи субъектов посреднических отношений, позволяющих исследовать эти отношения комплексно. В статье проводится комплексный анализ функций посредничества с позиции социологии, юриспруденции и экономических наук. Многие из функций, которые выделяют представители разных научных областей, совпадают по своему семантическому значению (например, информационная, коммуникативная и т.д.), в связи с чем, необходимо выработать единую классификацию, учитывающую всю многоаспектность посредничества и характеризующую его как общеправовой институт. Функциональный подход позволяет более глубоко изучить длительный процесс возникновения и развития посредничества, появления его различных типов, видов, форм в разных сферах общественных отношений, т.е. процесс формирования и эволюции посредничества. Исследование посредничества с позиции функционального анализа достигается в том числе и путем синтеза научных аспектов, разработанных различными отраслями знаний, внедрения научного инструментария, применяемого несколькими науками при одновременном использовании для решения конкретной задачи, что привело, в конечном итоге, к выработке теоретических моделей посредничества. Однако в статье ставится задача изучения посредничества не изолированно, а во взаимосвязи с другими правовыми явлениями, как производными от него, так и катализировавшими его развитие, а также в сравнительной взаимосвязи с его эволюционированием и регулированием в других правовых системах.

Ключевые слова: посредничество, теория, функции, анализ, теоретическая модель, информация, общественных отношения, субъект, законность.

В условиях усложнения социальных связей, интенсивного развития рыночных отношений, в условиях дифференциации отраслей и институтов права наблюдается также процесс их интеграции, усиления взаимосвязей. Этот объектив-

ный процесс ставит на первое место научные проблемы интегрального, системного значения, которые охватывают широкий комплекс правовых средств, воздействующих на общественное развитие. К их числу относится и проблема 
функционального анализа посредничества как общеправового института, включающая социально-экономические и политико-правовые аспекты правового воздействия.

Центральная ориентация функционализма - выраженная в практике интерпретации данных путем установления их значения для более крупных структур, в которые они входят,была обнаружена практически во всех науках о человеке: биологии, психологии, экономике и юриспруденции, антропологии и социологии. «Преобладание функционалистской точки зрения взгляда само по себе не гарантирует ее научной ценности, но все же наводит на мысль, что совместный опыт заставил обратиться к этой ориентации исследователей, специализирующихся в изучении человека как биологического организма, субъекта психической деятельности, члена общества и носителя культуры» [6]. На данный момент нам более важна та возможность, что предыдущий опыт других дисциплин может дать полезные методологические модели для функционального анализа посредничества.

Учитывая вышеизложенное и тот факт, что функциональный анализ представляет собой разновидность анализа, предполагающий рассмотрение объекта как комплекса выполняемых им функций, а не как материально-вещественных структур, он, тем самым позволяет абстрагироваться от конкретного исполнения объекта, и сосредоточить внимание на его функциях. Поиск альтернативных вариантов реализации функций осуществляется с целью снижения затраты и повышения уровня выполнения функции.

Социальные функции могут быть внешними - по отношению к той системе, элементом которой данный социальный институт является, и внутренними - в процессах организации социальных действий и регулирования социальных связей своего персонала. Как правило, «социальный институт - полифункционален, более того, его специфику определяет, с одной стороны, совокупность предписанных ему социальных функций, а с другой - главная (основная) социальная функция. Функционирование социального института предполагает достижение определенной цели и решение конкретных задач, при этом, результатами функционирования социального института могут быть созданные материальные и духовные ценности, удовлетворение личных и общественных потребностей и интересов, изменения в процессах общественной жизни. Результаты функционирования социального института свидетельствуют о его состоянии и развитии, служат отправной точкой для дальнейшего функционирования данного социального института и тех социальных институтов, которые с ним связаны» [3].

Посредничество предполагает наличие социальных функций, где одной из основных является функция распределительная, позволяющая объединить производителей и потребителей различного уровня: физиологических, потребности в безопасности, общении, самореализации в трудовой деятельности и т.п.

Другая значимая функция - информационная, которая заключается в возможностях и способностях получать, анализировать, систематизировать, распространять различную информацию, необходимую человеку, организациям в рыночных условиях; связана с поиском, куплей и продажей конфиденциальной рыночной информации, а также с владением ею.

Важной посреднической функцией является коммуникативная, поскольку она помогает устанавливать отношения между субъектами, представляя собой широчайший набор предлагаемых способов коммуникации - «от простого соединения (сведения) различных агентов рынка до заключения между ними совместных сделок с разнообразными формами участия в них самих посредников» [1].

Посредничество, рассматриваемое социологами, представляющее собой совокупность субъектов общества, вступающих в устойчивые отношения в процессе распределительной деятельности, характеризуется поведенческими социально значимыми признаками субъектов (удовлетворение потребностей, профессионализм, ответственность и т.д.), которые сочетаются с установками, требованиями, ценностями (законопослушность, социальная ответственность и т.д.).

Кроме того, выделяются функции посредничества как одного из альтернативных способов разрешения правовых конфликтов, о системе которых пойдет речь в следующем параграфе настоящего исследования. В этом методологическом ключе, автор полагает возможным рассматривать функции посредничества, проводя параллели с преимуществами самих альтернативных форм разрешения правовых конфликтов. 
Посредничество является объективной составляющей рыночной экономики и выступает неотъемлемым звеном продвижения товаров и услуг к потребителю. Соответственно, как и любой социальный институт, он базируется на определенных принципах и правилах, обуславливаемых законами экономики.

Функциональный анализ посредничества предполагает исследование последнего в качестве общеправового института, осуществляющего свою деятельность по различным направлениям, элементы которого находятся во взаимосвязи, взаимообусловленности и служат достижению единой, общей цели. Рассматриваемое в функциональном аспекте посредничество представляет собой сложную многоцелевую инструментальную систему, при помощи которой решаются задачи в различных сферах общественных отношений. Являясь интегрированной целостностью, эта система, кроме того, представляет собой взаимосвязанную и взаимообусловленную совокупность элементов, которые в рамках системы осуществляют деятельность по определенным направлениям. Но вместе с тем деятельность всех элементов системы подчинена единой целевой установке, что позволяет говорить об их системном и функциональном единстве.

Представляется возможным выделить следующие функции посредничества как общеправового института: регулирующая, определяющая структуру интересов общества, баланс интересов производства и потребления, интересов конфликтующих сторон; прогностическая, позволяющая предвидеть политику развития потребностей в обществе, отношения (в том числе конфликтные) между различными социальными слоями, ориентацию экономического мышления; стимулирующая, позволяющая выявить эффективность при разрешении правовых конфликтов, а также рациональность использования ресурсов человеком и обществом; распределительная, позволяющая объединить субъектов отношений в единую систему для удовлетворения потребностей различного уровня в обществе; информационная, заключающаяся в возможностях и способностях получать, анализировать, систематизировать, распространять различную информацию, необходимую самым разнообразным субъектам общественных отношений; коммуникативная, представляющая собой широчайший набор предлагаемых способов коммуникации - от простого сведения различных агентов рынка до заключения между ними совместных сделок с разнообразными формами участия в них самих посредников.

Кроме того, с учетом обозначенных выше позиций, функциональный анализ посредничества дает нам основания полагать, что: посредничество сближает интересы сторон (производителей и потребителей, сторон в правовом конфликте), предоставляя при этом различные виды посредников; при анализе функций посредничества на первый план выходят распределительные и информационные отношения и результаты деятельности посредников, оказывающие влияние на развитие общества в целом; важной особенностью в рассматриваемом ракурсе выступает система социального сотрудничества (партнерства), возникающая в процессе обмена ценностями, мнениями, информацией, суждениями между преследующими свои цели субъектами или конфликтующими сторонами; важной чертой функций посредничества является целенаправленная деятельность на эффективную организацию конкретного процесса, где участвует тот или иной вид посредника; посреднические функции реализуются не только в системе рыночного обмена (на чем ранее делался акцент в литературе), они характерны для множества социальных действий и взаимодействий людей, включенных в многообразную и многофункциональную систему социального обмена (социальных сетей) на различных уровнях организации общества.

\section{Библиографический список}

1. Абдуллина С.В. Социальный феномен посредничества: Дисс... канд.социол.наук. Уфа, 2011. 160 с.

2. Бродский М.Н., Бродский Г.М. Право и экономика: инвестиционное консультирование.- СПб: АООТ «Типография «Правда», 1999.- 496 с.

3. Глотов М.Б. Социальный институт: определение, структура, классификация. // Социологические исследования, 2003. № 10. С.13-19.

4. Донченко E.A., Титаренко Т.А. Личность: конфликт, гармония.- Киев: Издательство Киевского государственного университета, 1989. - 580 с. 
5. Запрудский Ю.Г. Социальный конфликт (политологический анализ). - Ростов: Тайп, 1992. - 586 с.

6. Мертон Р. Социальная теория и социальная структура. / Р. Мертон. М.: АСТ: АСТ МОСКВА ХРАНИТЕЛЬ, 2006, 873 c.

7. Тихомиров Ю.А. Юридическая коллизия.-М.: Юристъ, 1994.- 189 с. 